\title{
Active Role of the Necrotic Zone in Desensitization of Hypoxic Macrophages and Regulation of CSC-Fate: A hypothesis
}

\author{
Maryam Mehrabi ${ }^{1 *}$, Fatemeh Amini $^{2}$ and Shima Mehrabi ${ }^{3}$ \\ ${ }^{1}$ Independent Researcher, Newcastle, United Kingdom, 2Institute of Neuroscience and Psychology, University of Glasgow, \\ Glasgow, United Kingdom, ${ }^{3}$ Internal Medicine, Iran University of Medical Sciences, Tehran, Iran
}

\section{OPEN ACCESS}

Edited by:

Ala-Eddin Al Moustafa, Qatar University, Qatar

Reviewed by:

Margaret Ashcroft, University of Cambridge, United Kingdom

Paolo E. Porporato,

Università degli Studi di Torino, Italy

*Correspondence:

Maryam Mehrabi

maryam.a.mehrabi@gmail.com

Specialty section:

This article was submitted to Molecular and Cellular Oncology, a section of the journal

Frontiers in Oncology

Received: 31 March 2018 Accepted: 11 June 2018

Published: 25 June 2018

Citation: Mehrabi M, Amini F and Mehrabi S (2018) Active Role of the Necrotic

Zone in Desensitization of Hypoxic

Macrophages and Regulation of CSC-Fate: A hypothesis.

Front. Oncol. 8:235.

doi: 10.3389/fonc.2018.00235
Fast-proliferating cancer cells in the hypoxic region face a shortage of oxygen and nutrients, undergo necrotic cell death, and release numerous signaling components. Hypoxia-induced chemo-attractants signal for macrophages/monocytes to clear debris and return the system to steady state. Accordingly, macrophages arrange into prenecrotic positions, where they are continuously exposed to stress signals. It can thus be hypothesized that gradual alteration of gene expression in macrophages eventually turns off their phagocytic machinery. Uncleared cell corpses within the hypoxic region potentially provide a rich source of building blocks for anaerobic metabolism of cancer stem cells via macropinocytosis, and are conceivably implicated in tumor progression and invasion.

Keywords: necrotic zone, solid tumors, tumor-associated macrophages, macropinocytosis, cancer stem cells, anaerobic metabolism

\section{INTRODUCTION}

Chaotic cell death in the necrotic zone of solid tumors, occurring as a constituent of the stress response, results in the release of cytoplasmic cell contents $(1,2)$. The existence of such an area within the tumor evidences the inefficient clearance of cell debris by macrophages. Macrophages/ monocytes, which are recruited to this area following hypoxic induction of chemo-attractants and trails of necrotic debris, immobilize between non-necrotic and pre-necrotic zones (3). Following integration of stress signals in this microenvironment, macrophages undergo chromatin changes, such that the expression level of receptors safeguards tissue turn over and homeostasis $(2,4)$. As professional phagocytes, they have the opportunity to use any distinct mechanisms or a combination of receptors/co-receptors and bridging molecules to carry out this task, an example being the upregulation of "eat me" signals $(5,6)$. This process is not without end, however, and phagocytes most likely become desensitized after a few cycles of clearing debris due to activation of mechanisms, such as negative regulatory feedback loops (7). Following redundancy of this macrophage cohort, new blood monocytes are recruited by tumor tissue to deal with the task. This cycle continues and increasing numbers of monocytes recruited for clearing cell debris in this zone settle here and become redundant (8). Thus, it is a matter of course that an increased number of macrophages within the pre-necrotic zone is directly correlated with an elevated number of necrotic cell deaths and grade of carcinoma (9). Histopathology samples from patients of various carcinomas support this concept (10).

Recent clinical trials using blockers of immune checkpoints have been successful in improving patient conditions (11). This treatment strategy can be improved further by including molecules 
involved in the equation of clearing dead cells $(12,13)$. However, there are critical questions that need to be answered, one of which regards the role and function of macrophages located in different topological positions of solid tumors: namely the prenecrotic zone, surrounding blood vessels, and within the stroma microenvironment (3). Our assumption is that desensitization of macrophages, which are overwhelmed with a variety of stress signals and an enormous amount of cell debris within the necrotic zone, leaves the region uncleared. In this unfavorable condition, tumor cells adopt survival metabolic pathways and constitutively scavenge available building blocks from the extracellular environment (14). This is a point of crisis, providing necessary nutrients for the uncontrolled proliferation of cancer stem cells (CSCs), dispatching exosomes, cytokines, and other factors for paracrine activities, and generating the potential to make the tumor invasive. We propose a clinical benefit of interrupting the formation of such a microenvironment, or equally preventing the generation of a similar region during cancer treatments such as radiotherapy and chemotherapy (13).

\section{DEVELOPMENT OF CARCINOMAS}

Carcinomas account for $90 \%$ of all human cancers and originate within the epithelium. Formation of carcinoma initiates with abnormal proliferation of a single or small group of mutated cells, followed by selection for rapidly growing populations. Cells become malignant in a multistep process incorporating a progressive series of alterations. Many internal or environmental factors may be involved in this development, including radiation and chemical carcinogens, which initiate the process by inducing DNA damage, or phorbol ester, which stimulates cell proliferation through activation of protein kinase C. Various human cancers, such as liver and cervical carcinomas, are induced by viruses (15).

Evolution of the tumor mass leads to formation of an organlike structure with a multilayer epithelium, various cell types, and an extracellular matrix. Distribution of these components and their complex interactions often resemble those associated with developing organs; this organization assists pathologists to classify the stage of malignancy (16). Phenotypic modifications of these cells occur under the influence of numerous factors within the tumor microenvironment (TME), such as IL-4, IL-13, TGF $\beta$, and IL-10. Tumor-associated macrophages (TAMs) do not fit in any rigid classification of macrophages, but for the most part resemble the M2 class (17). These cells express a series of markers, including CD163, the Fc fragment of IgG, C-type lectin domains, and heat shock proteins (18-20), and secrete mitogenic factors for neoplastic cells which potentiate tumor growth, promote angiogenesis, and enable metastatic spread (21). TAMs stimulate tumor distribution through interaction with the receptor activator of the NF- $\kappa \mathrm{B}$ ligand (EGF or RANKL) secreted by tumor cells (22).

\section{HYPOXIA AND THE NECROTIC ZONE}

Solid tumors are highly heterogeneous, and often exhibit low oxygen tension which increases with size (23). Cell outgrowth and shortage of blood vessels results in the formation of hypoxic regions; specifically, $0.08 \mathrm{mmHg}_{2}$ in tumors larger than $2 \mathrm{~cm}^{3}$ compared to $66 \mathrm{mmHg}$ in normal tissue (24). Available oxygen within the tumor mass is consumed by cells close to vasculature, meaning that distant, proliferating cells face a lack of oxygen and nutrients; consequently, most of them undergo cell death and generate a necrotic zone. Cells that are clonally selected by this microenvironment are resistant to hypoxia, cell death, and therapeutic methods (25), and form the most invasive CSCs $(26,27)$.

Data from in vivo models of carcinoma and $3 \mathrm{D}$ spheroid cultures strongly suggest that necrotic cell death occurs at a strikingly constant distance from blood vessels (28-30). Development of cell death due to diffusion gradients follows a progressive course across three separate zones: proliferation at the outer zone, differentiation in the middle zone, and eventual, central cell death (Figure 1A). The central zone, which develops to a predictable radius of $300-400 \mu \mathrm{m}$, is initially necrotic, and apoptosis occurs as the spheroidal diameter increases (31).

The topography of necrosis is a major determinant of the rate of cell proliferation to angiogenesis, and is an independent prognostic factor for patients with renal, lung, thyroid, and colorectal carcinoma. A substantial proportion of necrosis in histopathology samples have been proposed as indicators of tumor aggressiveness, which generally leads to a poor clinical outcome (32-35). Clinical data show that TAMs immobilize between transient (avascular and non-necrotic) and pre-necrotic areas of human breast tumors $(36,37)$, and prostate (38), endometrial (39), ovarian (40), and lung carcinomas (41).

\section{HYPOXIC TME DEFINES CSC-FATE}

Emerging evidence suggests that hypoxic TME can potentially regulate cell fate and enrich the stem cell phenotype of cancer cells (42-44). Tumor cells located in the hypoxic region of clinical samples express stem cell-associated genes and show strong nuclear accumulation of hypoxia-inducible factor- $1 \alpha$ (HIF-1 $\alpha)$ protein (45-47). Previous research has established that HIF proteins activate-specific signaling pathways, such as Notch, as well as the expression of transcription factors such as Oct4 that dictate multipotency and stem cell self-renewal. Additionally, oxygenindependent oncogenic signaling pathways, such as PI3K/Akt, IGF2/IGF1R, and TGF $\alpha /$ EGFR, can stabilize HIF proteins (48). In a systematic literature review, Keith and Simon suggest that "hypoxic tumor tissues could be a breeding ground for cancer stem cells" (49).

\section{CLEARANCE OF THE NECROTIC ZONE}

Clearance of dead cells and debris is an important regulatory mechanism that has been conserved throughout evolution to serve the regulation of normal tissue homeostasis. The turnover rate of removing dead cells has been estimated to be one million cells per second (50). This process is extremely high capacity and efficient, such that dead cells are rarely seen in healthy individuals. Several steps are involved in prompt cell clearance, including recruitment of macrophages, sensing apoptotic and necrotic cells via "find me" signals, recognition via "eat me" signals, the 

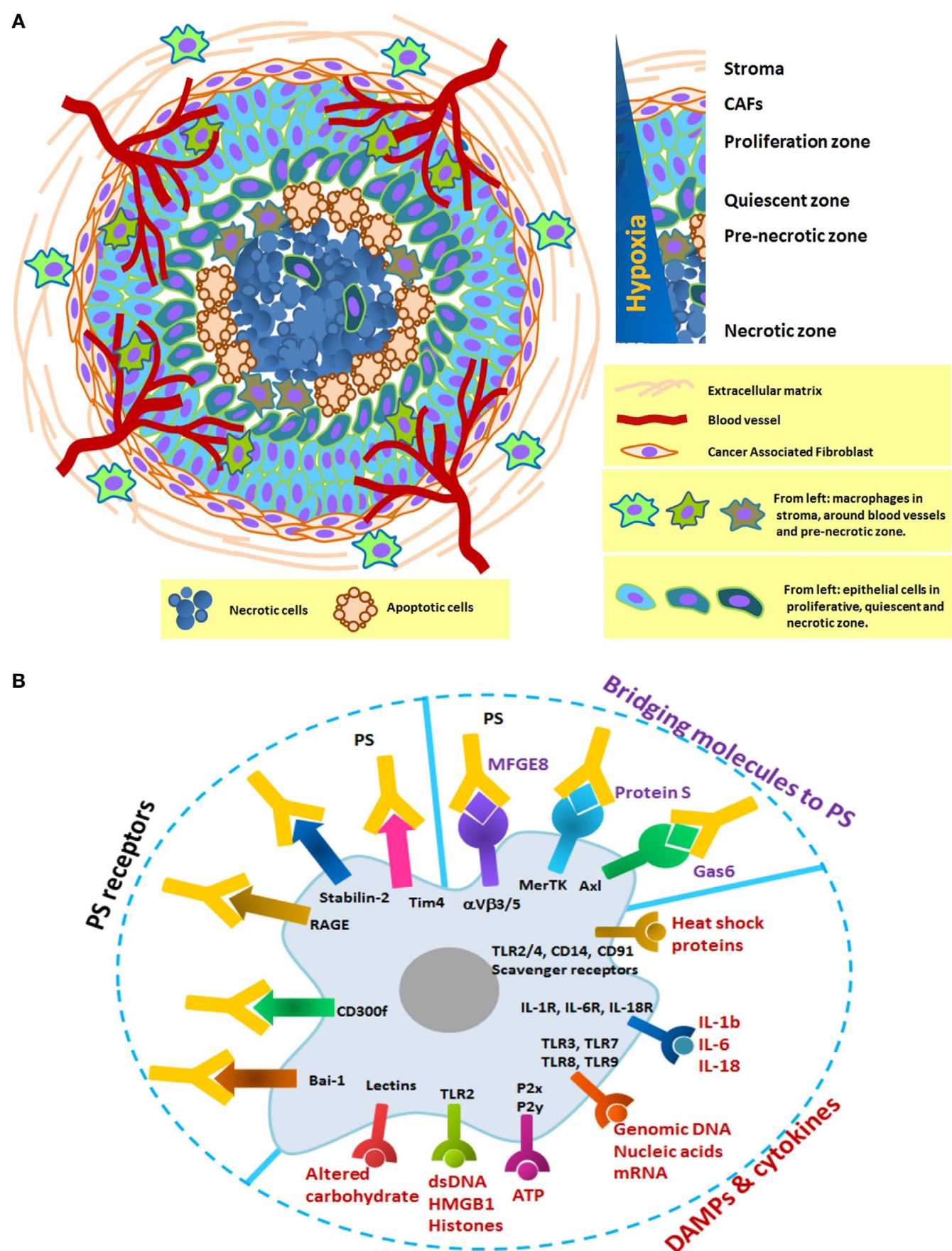

FIGURE 1 | (A) Schematic formation of a distinct necrotic zone in carcinoma and immobilization of macrophages in three distinct areas: the stroma, the vicinity of blood vessels, and the pre-necrotic zone. Tumor macrophages originate from tissue-resident cells or blood monocytes and adapt to perform a specific function depends on their local microenvironment. In hypoxia, they progressively change from M1 to M2-like phenotype with poor antigen presentation and increase in number as tumor grows. Their receptors in this zone are continuously engaged with necrotic debris and apoptotic cells. There is, therefore, a definite need to look at the prolonged changes in the phagocytic machinery of macrophages. (B) Selected macrophage receptors that potentially mediate recognition of damageassociated molecular patterns (DAMPs), cytokines, and PS in the necrotic zone. DAMPs and cytokines can activate macrophages through the multiple surface receptors. Exposed PS on the surface of necrotic debris or apoptotic cells can be recognized directly by PS receptors (Bai-1, Tim4, etc.) or indirectly by bridging molecules (Gas6, protein S, and MFGE8).

signaling pathways that regulate cytoskeletal rearrangements necessary for engulfment, and the immune response of phagocytes in the clearance event.
Development of the necrotic zone in carcinomas is an ongoing, dynamic process. Necrotic cell death in the hypoxic microenvironment is rapid and extensive, and secondary necrosis of 
apoptotic cells is also common, such that macrophages cannot clear debris in a timely and efficient manner. Confusion regarding the role of necrotic cells in the development of solid tumors is widespread, as it is associated with compensatory cell proliferation and inflammation. In fact, several reports suggest that inhibition of cell death is protective against cancer development (51-55).

Necrotic corpses, apoptotic cells, and CSCs in contact with pre-necrotic macrophages can trigger engulfment $v i a$ interaction with phagocytic receptors capable of decoding their cognate ligands. Even subtle differences in the internalized ligands could have far-reaching consequences on antigen presentation to $\mathrm{T}, \mathrm{B}$, and NK cells and become the key determinant of immunogenic or tolerogenic responses. Here, we present a conceptual overview using selected studies to propose an active role for the necrotic zone in tumor progression and invasion.

Intolerable conditions within hypoxic lesions of tumors induce chaotic breakdown of cells, resulting in infiltration of increased macrophages/monocytes. The pattern of migration is partly due to hypoxic induction of chemo-attractants, such as VEGF, CCL2, and CCL5, as well as "find-me" and danger signals along a trail of necrotic debris $(56,57)$. This is likely important for maximizing their opportunity to clear cell debris. Cytosolic constituents pouring into the microenvironment through the damaged membrane can interact with phagocytic receptors and initiate internalization of necrotic targets through macropinocytic mechanisms. Such eat-me signals include endogenous danger signals loaded with heat shock proteins, nuclear proteins like high-mobility group box-1 protein (HMGB1), histones, ATP, DNA, RNA, other nucleotides, and components of the extracellular matrix that are cleaved by cellular proteases (58-60). Negatively exposed phosphatidylserine (PS) is also involved in the recognition and engulfment of necrotic cells, but with a distinct and non-competitive mechanism compared to apoptotic cells $(60,61)$.

\section{HOW MACROPHAGES CLEAR DEBRIS}

Macropinocytosis enables macrophages to continuously sample and internalize their extracellular environment at a rate of up to twice their surface area per hour. They use distinct and often unrelated receptors and bridging molecules, meaning that complete inhibition of engulfment machinery has never been achieved. This highly redundant system with various receptors mediates recognition of damage-associated molecular patterns (DAMPs), including heat shock proteins, cytokines, DNA, RNA, metabolic ATP, HMGB1, histones, and altered carbohydrates. Exposed PS on the surface of necrotic corpses is recognized directly by its receptors (Tim4, stabilin-2, RAGE, CD300f, and Bai-1) or indirectly by bridging molecules (Gas6, Protein S, and MFGE8) (Figure 1B). In general, the physiology of macrophages dramatically alters following uptake of these components, leading to modification of protein expression and cytokine production. Internalized antigens are processed and loaded onto $\mathrm{MHC}$ molecules for presentation to immune cells (62). Both MHC class I and II have been identified on macropinosome-like structures (63-65). The macropinocytic process is expected to provoke an inflammatory response (66). However, contradictory results from cancer patients and in vivo models support the complexity of the TME $(60,67)$.

\section{POTENTIAL MECHANISMS IN HAMS ALTERATION}

\section{Chromatin Remodeling}

The necrotic zone is a non-resolving inflammatory condition, and macrophages/monocytes continue to enter the zone and differentiate as the lesion progresses. DAMPs derived from necrotic cancer cells can foster this chronic condition through stimulation of TLRs and specific plasma membrane receptors in macrophages (Figure 1B). With enormous functional plasticity, HAMs integrate these signals, leading to alteration of their regulatory state and transcriptional program. For example, HMGB1 activates an immune response via TLR signals and regulates intracellular transcription (68).

Molecular studies of macrophages show similar trends in response to a single polarizing stimulus. Results obtained from gene expression profiling of a 20,000-element cDNA microarray in LPS-stimulated murine macrophages show major changes in expression of a broad range of genes with comparison to normal tissue (4, 69-72). Interestingly, the expression level of these genes across five-time points after LPS challenge has a profound effect on the macrophage transcriptome, and both differentiated TRMs and monocyte-derived macrophages become less plastic over time (73-76). Most of the genes initially expressed at a high level are repressed, as if to accommodate the new spectrum of induced genes. Genes which were initially undetectable are promoted, and very few elements also remain static. Every macrophage population in these experiments is likely to be different (77). A similar tendency has been reported in response to other stimuli, including a TLR2-ligand (MALP2), a TLR9-ligand (CpGs), M-CSF (78), GM-CSF (79), and exposure to cytokines, such as IL-1 $\beta$, IL-4, tumor necrosis factor (TNF) $\alpha$, IFN $\gamma$, or TGF $\beta$ (80). Results suggest that changes are persistent even after stress signal exposure is seized, and are faster and stronger with each consecutive exposure.

The phenotype of macrophages during hypoxia is expected to be similar to that of LPS-stimulated macrophages, which is M1-like. However, HAMs are associated with an M2-like response (81). In vivo tumor models of glioma and breast cancer have demonstrated macrophage migration as a function of hypoxia, and suggest evolving polarization to M2, concomitant to the hypoxic shift within the growing tumor $(82,83)$. Taken together, these results appear to support our assumption that continuous exposure to a broad range of stimuli determines a continuum of distinct transcriptional and functional output in HAMs. As time goes on, HAMs exhibit gradual changes in their receptor expression anywhere between M1 and M2. In fact, the engulfment machinery of macrophages is engaged with a continuous cycle of necrotic debris, leading to significant, prolonged changes in involved receptors. Disarmed macrophages are not able to recruit or present antigens to other immune cells and block the adaptive immune response. Macrophages may eventually become 
senescent or undergo necrotic cell death, thus joining the crew of the necrotic zone.

\section{The Hypoxic Response}

Macrophages respond to hypoxia through activation of the transcription factor, hypoxia-inducible factor-1, which is an oxygen sensor and plays a significant role in macrophage polarization (84). This master transcription factor is regulated by nuclear factor- $\kappa \mathrm{B}(\mathrm{NF}-\kappa \mathrm{B})$ and induces profound changes in the expression level of angiogenesis- and metastasis-related genes, such as VEGF, FGF2, MMP7, and MMP9 (38, 52, 53, 85). Consequent to this is recruitment of more macrophages, and release of pro-inflammatory cytokines, such as TNF $\alpha$, IL- $1 \beta$, MIF, CCL3, and COX2, as well as M2 markers, such as IL-10 and arginase 1. A clear link between the HIF responses of innate immunity and cellular processes that aid the engulfment processes in macrophages has been established in previous research $(86,87)$. The continued upregulation of HIF is part of the regenerative and immunosuppressive response (88).

\section{Negative Regulatory Feedback Loops}

Here, we argue that continuous inflammatory events within the necrotic zone cause prolonged changes in macrophage phagocytic receptors. A well-known example is aberrant expression of TAM-receptors (Tyro, Axl, Mer) during tumor progression in many cancers (89).

Binding of inflammatory cytokines to TLRs and costimulatory receptors in HAMs can result in activation of signaling cascades, causing upregulation of TAM-receptors. The innate immune response is a carefully regulated system, meaning that unrestrained signaling by TLRs and cytokine receptors is not supported. A notable mechanism to inhibit these immune responses in APCs is the negative regulatory pathway driven by the TAM-receptor tyrosine kinases. These receptors bind their cognate ligand using bridging molecules, like Gas6 or protein $S$, which sit between them and PS on the surface of apoptotic cells, necrotic debris, and CSCs. The suppressor of cytokine signaling proteins (SOCS1 and SOCS3) are among the most important genes that are induced by this negative feedback loop. TAM-receptor signaling also inhibits TLR3, TLR4, and TLR9 activation and their multiple points in signal transduction cascades, including the activation of the p38 mitogenactivated protein kinase, extracellular-signal-regulated kinase 1 (ERK1/ERK2), NF- $\mathrm{BB}$, and TNF-receptor-associated factor (TRAF3 and TRAF6). TLR-induced production of proinflammatory cytokines, including $\mathrm{TNF} \alpha$, interleukins (IL-6, IL-12), and type 1 interferons (IFNs), are also inhibited as result of this signaling (90). Our assumption is that this feedback loop is likely to desensitize macrophage receptors in the hypoxic area and reduce their rate of turn over and phagocytic uptake.

\section{Immune Checkpoints}

The reduced phagocytic capacity of HAMs could also be a consequence of signaling pathways triggered by immune checkpoints. Increased expression in tumor cells of such signals, like CD47 and programmed death-ligand 1 (PD-L1), is proposed to be a mechanism through which cancer cells induce "don't eat me" signals and evade immune detection by $\mathrm{T}$ cells. Immune checkpoint blockade has been the subject of multiple clinical trials in cancer, but has tended to focus on the functional consequences of $\mathrm{T}$ cells rather than macrophages $(11,91,92)$. Interestingly, a limited number of research has demonstrated an increase in phagocytosis and reduction in tumor growth in a macrophagedependent fashion $(93,94)$.

Overexpression of CD47 in cancer cells activates $\operatorname{SIRP} \alpha$, which is an inhibitory receptor expressed mainly by myeloid cells. Upon binding CD47, SIRP $\alpha$ initiates a signaling cascade through phosphorylation of the immunoreceptor tyrosinebased inhibition motifs on its cytoplasmic tail (95). Subsequent binding and activation of SHP-1 and SHP-2 in macrophages prevents accumulation of myosin-IIA at the phagocytic synapse and blocks phagocytosis (96). Antibody blocking of this regulatory signal in normal tissue does not induce phagocytosis, although it does turn off the "don't-eat-me" signal; this is owing to the fact that in the absence of CD $47 / \mathrm{SIRP} \alpha$ signaling, a secondary pro-phagocytic "eat-me" signal is required to subject cells to phagocytosis (12). There are several "eat-me" signals which have the potential to trigger this process, such as surface calreticulin (CRT) and PS $(97,98)$. Cell-surface CRT is present on a subset of all solid tumors, with no expression on normal cells (99). CRT interacts with CD91 on macrophages and is required for phagocytosis of tumor cells following neutralization of the CD47/SIRP $\alpha$ interaction (100). It has been reported that cell-surface expression of CRT is controlled by the TLR-Btk pathway, and that a TLR4 agonist is necessary for activation of macrophages after blocking of the CD47/SIRP $\alpha$ interaction (101).

Another clinically successful immune checkpoint, the PD-1 receptor, is primarily known for its role in the inhibition of stimulated T cells (102). Its phagocytic effect, however, has recently been considered. TAMs in humans express variable levels of PD-1 which increase with tumor progression in the M2 subset, and their upregulation over time correlates negatively with phagocytic potency against tumor cells in human cancer. $\mathrm{PD}-\mathrm{L} 1$ removal in animal models rescues $\mathrm{PD}-1^{+}$phagocytosis in macrophages and decreases tumor size. The M2 subset of TAMs mainly originates from bone marrow and resides in the inflammatory TME (103).

\section{Final Thoughts}

Here, we have focused on the role of HAMs in the clearance of cell debris resulting from stress stimuli in the necrotic zone of solid tumors. The aim has been to highlight how the engulfment machinery of macrophages may alter due to interaction with endogenous danger signals. This alteration may worsen over time because of continuous exposure to presented stimuli. Therefore, the uncleared necrotic zone is perhaps the most strategic region in carcinoma, an area in which CSCs can ingest essential building blocks for their survival and maintain anaerobic metabolism in the hypoxic microenvironment. Consequently, cells growing within this harsh milieu are highly aggressive and capable of developing drug and therapeutic resistance. Further proliferation of CSCs jointly with necrotic corpses could tear the carcinoma 


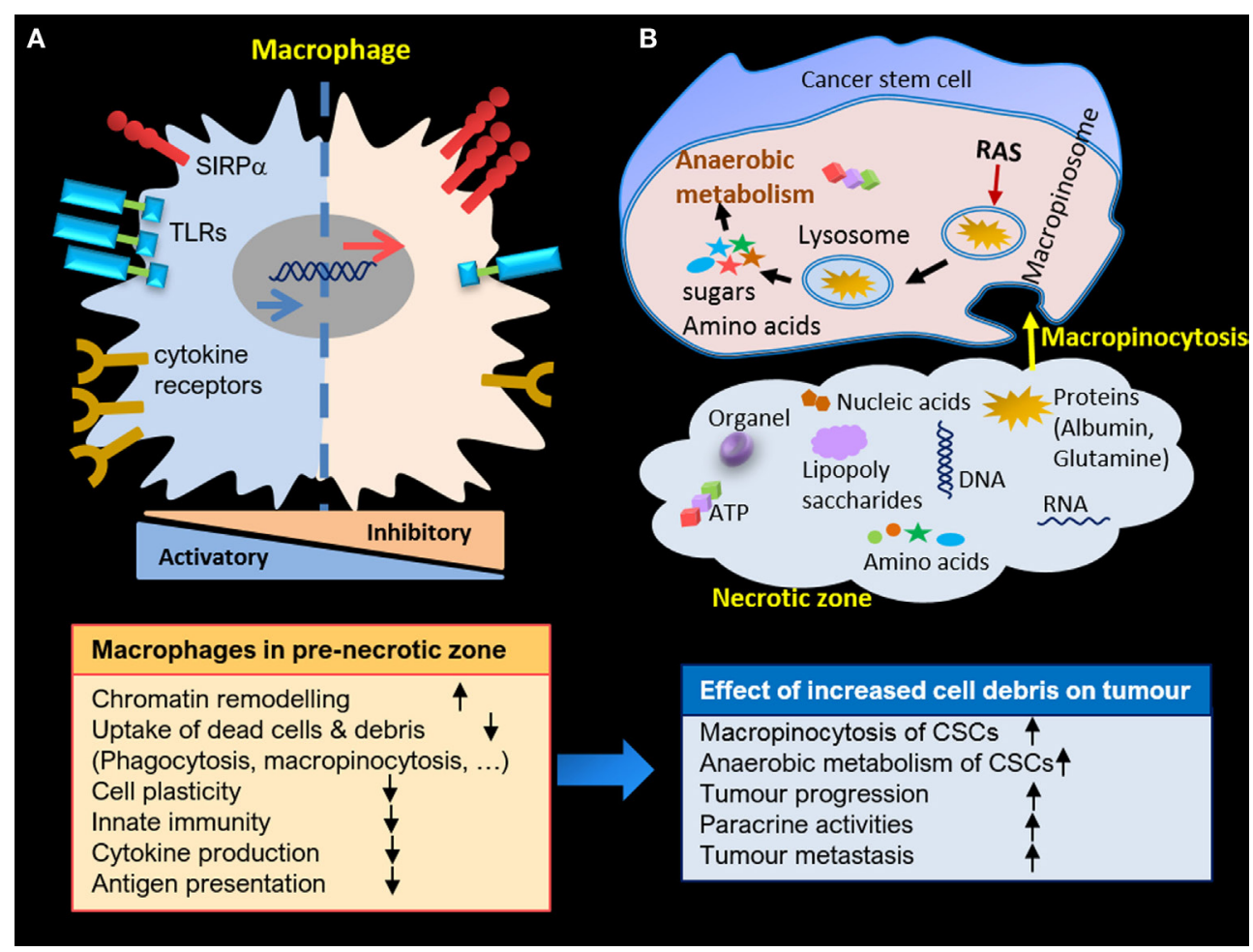

FIGURE 2 | (A) Macrophage alteration in pre-necrotic zone and gradual loss of activities due to continuous exposure to cell debris. (B) Anaerobic metabolism of cancer stem cells (CSCs) in necrotic zone through macropinocytosis, and enhanced proliferation and paracrine activities of CSCs due to accumulation of cell debris in necrotic zone.

capsule, resulting in their deposition in blood vessels, lymph nodes, and ultimately resulting in metastasis (Figure 2).

The key to avoiding these processes, therefore, is to clear necrotic debris in the initial stages, with the implication that engulfment machinery of HAMs should be up and running with no alteration. Treatment of HAMs with any agent, however, will not be the answer, as they are under the continuous influence of necrotic debris. A potential therapeutic target would be the genetic modification of macrophages for key engulfment receptors. Gene delivery vehicles could also be transported directly to on-site macrophages. We speculate that this strategy may partly preserve both the engulfment capacity and the immunogenicity of macrophages against CSCs, as phagocytosis is the gatekeeper for immune responses against danger signals.

Another implication of this hypothesis would be to avoid inducing further hypoxic cell death during therapeutic courses. Considering this strategy in conjunction with imaging

\section{REFERENCES}

1. Wynn T, Chawla A, Pollard JW. Origins and hallmarks of macrophages: development, homeostasis and disease. Nature (2013) 496(7446):445. doi:10.1038/nature12034

2. Chovatiya R, Medzhitov R. Stress, inflammation, and defence of homeostasis. Mol Cell (2014) 54(2):281-8. doi:10.1016/j.molcel.2014.03.030

3. Qian BZ, Pollard JW. Macrophage diversity enhances tumor progression and metastasis. Cell (2010) 141:39-51. doi:10.1016/j.cell.2010.03.014 technologies and computational modeling of the TME would allow surgeons to choose a better approach to eradicate a mass of solid tumor.

\section{NOTATIONS}

Macrophages refer to tissue-resident population, TAMs: tumor-associated macrophages (TAMs) regardless of their position, and hypoxic-TAMs (HAMs) denotes TAMs allocated in the pre-necrotic zone of solid tumor, TAM-receptors: Tyro, Axl, Mer.

\section{AUTHOR CONTRIBUTIONS}

MM: conception and design of manuscript, research of supporting evidence, writing and design of figures. FA and SM: editing, critical revision of content and final approval.

4. Ravasi T, Wells C, Forest A, Underhill DM, Wainwright BJ, Aderem A, et al Generation of diversity in the innate immune system: macrophage heterogeneity arises from gene autonomous transcriptional probability of individual inducible genes. J Immunol (2002) 168:44-50. doi:10.4049/jimmunol.168.1.44

5. Gordon S, Martinez-Pomares L. Physiological roles of macrophages. Eur J Physiol (2017) 469:365-74. doi:10.1007/s00424-017-1945-7

6. Krysko DV, D'Herde K, Vandennabeele P. Clearance of apoptotic and necrotic cells and its immunological consequences. Apoptosis (2006) 11:1709-26. doi:10.1007/s10495-006-9527-8 
7. Lemke G, Rothlin CV. Immunobiology of TAM receptors. Nat Rev Immunol (2008) 8(5):327-36. doi:10.1038/nri2303

8. Lahmar Q, Keirsse J, Laoui D, Movahedi K, Van Overmeire E, Van Ginderachter JA. Tissue-resident versus monocyte-derived macrophages in the tumor microenvironment. Biochim Biophys Acta (2016) 1865:23-4. doi:10.1016/j.bbcan.2015.06.009

9. Ostuni R, Kratochvill F, Murray PJ, Natoli G. Macrophages and cancer: from mechanisms to therapeutic implications. Trends Immunol (2015) 36(4):229-39. doi:10.1016/j.it.2015.02.004

10. Caruso R, Parisi A, Bonanno A, Paparo D, Quattrocchi E, Branca G, et al. Histologic coagulative tumor necrosis as a prognostic indicator of aggressiveness in renal, lung, thyroid and colorectal carcinomas: a brief review. Oncol Lett (2012) 3:16-8. doi:10.3892/ol.2011.420

11. Pardoll DM. The blockade of immune checkpoints in cancer immunotherapy. Nat Rev Cancer (2012) 12:252-64. doi:10.1038/nrc3239

12. Willingham SB, Volkmer JP, Gentles AJ, Sahoo D, Dalerba P, Mitra SS, et al. The CD47-signal regulatory protein alpha (SIRPa) interaction is a therapeutic target for human solid tumors. Proc Natl Acad Sci U S A (2012) 109(17):6662-7. doi:10.1073/pnas.1121623109

13. Sulciner ML, Serhan CN, Gilligan MM, Mudge DK, Chang J, Gartung A, et al. Resolvins suppress tumor growth and enhance cancer therapy. J Exp Med (2018) 215(1):115-40. doi:10.1084/jem.20170681

14. Pavlova NN, Thompson CB. The emerging hallmarks of cancer metabolism. Cell Metab (2015) 23:27-47. doi:10.1016/j.cmet.2015.12.006

15. Cooper GM. The Cell: A Molecular Approach. 2nd ed. Cooper GM, editor. Boston University, Sunderland (MA): Sinauer Associates (2000).

16. Condeelis J, Pollard JW. Macrophages: obligate partners for tumor cell migration, invasion, and metastasis. Cell (2006) 124:263-6. doi:10.1016/j. cell.2006.01.007

17. Pollard JW. Trophic macrophages in development and disease. Nat Rev Immunol (2009) 9:259-70. doi:10.1038/nri2528

18. Biswas SK, Gangi L, Paul S, Schioppa T, Saccani A, Sironi M, et al. A distinct and unique transcriptional program expressed by tumor-associated macrophages (defective NF-kappaB and enhanced IRF-3/STAT1 activation). Blood (2005) 107(5):2112-22. doi:10.1182/blood-2005-01-0428

19. Sakai Y, Honda M, Fujinaga H, Tatsumi I, Mizukoshi E, Nakamoto Y, et al. Common transcriptional signature of tumor-infiltrating mononuclear inflammatory cells and peripheral blood mononuclear cells in hepatocellular carcinoma patients. Cancer Res (2008) 68(24):10267-79. doi:10.1158/00085472.CAN-08-0911

20. Beck AH, Espinosa I, Edris B, Li R, Montgomery K, Zhu S, et al. The macrophage colony-stimulating factor 1 response signature in breast carcinoma. Clin Cancer Res (2009) 15(3):778-87. doi:10.1158/1078-0432.CCR08-1283

21. Coussens LM, Zena Werb Z. Inflammation and cancer. Nature (2002) 420(6917):860-7. doi:10.1038/nature01322

22. Luo JL, Tan W, Ricono JM, Korchynskyi O, Zhang M, Gonias SL, et al. Nuclear cytokine-activated IKKalpha controls prostate cancer metastasis by repressing Maspin. Nature (2007) 446:690-4. doi:10.1038/nature05656

23. Gilkes DM, Semenza GL, Wirtz D. Hypoxia and the extracellular matrix: drivers of tumour metastasis. Nat Rev Cancer (2014) 14(6):430-9. doi:10.1038/ $\operatorname{nrc} 3726$

24. Hockel M, Vaupel P. Tumor hypoxia: definitions and current clinical, biologic, and molecular aspects. J Natl Cancer Inst (2001) 93:266-76. doi:10.1093/ jnci/93.4.266

25. Graeber TG, Osmanian C, Jacks T, Housman DE, Koch CJ, Lowe SW, et al. Hypoxia-mediated selection of cells with diminished apoptotic potential in solid tumours. Nature (1996) 379:88-91. doi:10.1038/379088a0

26. Dong Z, Wang JZ, Yu F, Venkatachalam MA. Apoptosis-resistance of hypoxic cells: multiple factors involved and a role for IAP-2. Am J Pathol (2003) 163:663-71. doi:10.1016/S0002-9440(10)63693-0

27. Polyak K, Weinberg RA. Transitions between epithelial and mesenchymal states: acquisition of malignant and stem cell traits. Nat Rev Cancer (2009) 9:265-73. doi: $10.1038 / \mathrm{nrc} 2620$

28. Jones B, Camplejohn RS. Stathmokinetic measurement of tumor cell proliferation in relation to vascular proximity. Cell Tissue Kinet (1983) 16:351-5.

29. Thomlinson RH, Gray LH. The histological structure of some human lung cancers and the possible implications for radiotherapy. Br J Cancer (1955) 9:539-49. doi:10.1038/bjc.1955.55
30. Tannock IF. The relationship between cell proliferation and the vascular system in a transplanted mouse mammary tumor. Br J Cancer (1968) 22:258-73. doi:10.1038/bjc. 1968.34

31. Bell HS, Whittle IR, Walker M, Leaver HA, Wharton SB. The development of necrosis and apoptosis in glioma: experimental findings using spheroid culture systems. Neuropathol Appl Neurobiol (2001) 27(4):291-304. doi:10.1046/j.0305-1846.2001.00319.x

32. Cheville JC, Lohse CM, Zincke H, Weaver AL, Blute ML. Comparisons of outcome and prognostic features among histologic subtypes of renal cell carcinoma. Am J Surg Pathol (2003) 27:612-624.

33. Pollheimer MJ, Kornprat P, Lindtner RA, Harbaum L, Schlemmer A, Rehak P, et al. Tumour necrosis is a new promising prognostic factor in colorectal cancer. Hum Pathol (2010) 41:1749-1757. doi:10.1016/j. humpath.2010.04.018

34. Collins J, Epstein JI. Prognostic significance of extensive necrosis in renal cell carcinoma. Hum Pathol (2017) 66:108-14. doi:10.1016/j.humpath. 2017.06.010

35. Enzinger FM, Folpe A, Weiss SW. Soft Tissue Tumors. 6th ed. Philadelphia: Elsevier Saunders (2014). p. 1-18.

36. Leek RD, Lewis CE, Whitehouse R, Greenall M, Clarke J, Harris AL. Association of macrophage infiltration with angiogenesis and prognosis in invasive breast carcinoma. Cancer Res (1996) 56:4625-9.

37. Leek RD, Landers RJ, Harris AL, Lewis CE. Necrosis correlates with high vascular density and focal macrophage infiltration in invasive carcinoma of the breast. Br J Cancer (1999) 79:991-5. doi:10.1038/sj.bjc.6690158

38. Burke B, Tang N, Corke KP, Tazzyman D, Ameri K, Wells M, et al. Expression of HIF- $1 \alpha$ by human macrophages: implications for the use of macrophages in hypoxia-regulated cancer gene therapy. J Pathol (2002) 196(2):204-12. doi:10.1002/path.1029

39. Ohno S, Ohno Y, Suzuki N, Kamei T, Koike K, Inagawa H, et al. Correlation of histological localization of tumor-associated macrophages with clinicopathological features in endometrial cancer. Anticancer Res (2004) 24: $3335-42$.

40. Negus RP, Stamp GW, Hadley J, Balkwill FR. Quantitative assessment of the leukocyte infiltrate in ovarian cancer and its relationship to the expression of C-C chemokines. Am J Pathol (1997) 150:1723-34.

41. Kim MS, Kwon HJ, Lee YM, Baek JH, Jang JE, Lee SW, et al. Histone deacetylases induce angiogenesis by negative regulation of tumor suppressor genes. Nat Med (2001) 7:437-43. doi:10.1038/86507

42. Kim H, Lin Q, Glazer PM, Yun Z. The hypoxic tumor microenvironment in vivo selects the cancer stem cell fate of breast cancer cells. Breast Cancer Res (2018) 20:16. doi:10.1186/s13058-018-0944-8

43. Yun Z, Lin Q. Hypoxia and regulation of cancer cell stemness. Adv Exp Med Biol (2014) 772:41-53. doi:10.1007/978-1-4614-5915-6_2

44. Mohyeldin A, Garzon-Muvdi T, Quinones-Hinojosa A. Oxygen in stem cell biology: a critical component of the stem cell niche. Cell Stem Cell (2010) 7(2):150-61. doi:10.1016/j.stem.2010.07.007

45. Vaupel P, Briest S, Hockel M. Hypoxia in breast cancer: pathogenesis, characterization and biological/therapeutic implications. Wien Med Wochenschr (2002) 52(13-14):334-42. doi:10.1046/j.1563-258X.2002.02032.x

46. Li Z, Bao S, Wu Q, Wang H, Eyler C, Sathornsumetee S, et al. Hypoxiainducible factors regulate tumorigenic capacity of glioma stem cells. Cancer Cell (2009) 15(6):501-13. doi:10.1016/j.ccr.2009.03.018

47. Pietras A, Hansford LM, Johnsson AS, Bridges E, Sjölund J, Gisselsson D, et al. HIF- $2 \alpha$ maintains an undifferentiated state in neural crest-like human neuroblastoma tumorinitiating cells. Proc Natl Acad Sci U S A (2009) 106(39):16805-10. doi:10.1073/pnas.0904606106

48. Semenza GL. Targeting HIF-1 for cancer therapy. Nat Rev Cancer (2003) 3:721-32. doi: $10.1038 / \mathrm{nrc} 1187$

49. Keith B, Simon MC. Hypoxia-inducible factors, stem cells and cancer. Cell (2007) 129:465-72. doi:10.1016/j.cell.2007.04.019

50. Ravichandran KS. Find-me and eat-me signals in apoptotic cell clearance: progress and conundrums. J Exp Med (2010) 207(9):1807-17. doi:10.1084/ jem.20101157

51. Pierce RH, Vail ME, Ralph L, Campbell JS, Fausto N. Bcl-2 expression inhibits liver carcinogenesis and delays the development of proliferating foci. Am J Pathol (2002) 160:1555-60. doi:10.1016/S0002-9440(10)61101-7

52. Malhi H, Gores GJ, Lemasters JJ. Apoptosis and necrosis in the liver: a tale of two deaths? Hepatology (2006) 43:S31-44. doi:10.1002/hep.21062 
53. Vick B, Weber A, Urbanik T, Maass T, Teufel A, Krammer PH, et al. Knockout of myeloid cell leukemia-1 induces liver damage and increases apoptosis susceptibility of murine hepatocytes. Hepatology (2009) 49:627-36. doi:10.1002/ hep. 22664

54. Nakamoto Y, Kaneko S, Fan H, Momoi T, Tsutsui H, Nakanishi K, et al. Prevention of hepatocellular carcinoma development associated with chronic hepatitis by anti-fas ligand antibody therapy. J Exp Med (2002) 196:1105-11. doi:10.1084/jem.20020633

55. Labi V, Erlacher M. How cell death shapes cancer. Cell Death Dis (2015) 6(3):e1675. doi:10.1038/cddis.2015.20

56. Murdoch C, Giannoudis A, Lewis CE. Mechanisms regulating the recruitment of macrophages into hypoxic areas of tumors and other ischemic tissues. Blood (2004) 104:2224-34. doi:10.1182/blood-2004-03-1109

57. Bottazzi B, Walter S, Govoni D, Colotta F, Mantovani A. Monocyte chemotactic cytokine gene transfer modulates macrophage infiltration, growth, and susceptibility to IL-2 therapy of a murine melanoma. J Immunol (1992) 148(4):1280-5.

58. Zhang X, Mosser DM. Macrophage activation by endogenous danger signals. J Pathol (2008) 14:161-78. doi:10.1002/path.2284

59. Hirt UA, Leist M. Rapid, noninflammatory and PS-dependent phagocytic clearance of necrotic cells. Cell Death Differ (2003) 10:1156-64. doi:10.1038/ sj.cdd. 4401286

60. Brouckaert G, Kalai M, Krysko DV, Saelens X, Vercammen D, Ndlovu M, et al. Phagocytosis of necrotic cells by macrophages is phosphatidylserine dependent and does not induce inflammatory cytokine production. Mol Biol Cell (2004) 15:1089-100. doi:10.1091/mbc.e03-09-0668

61. Cocco RE, Ucker DS. Distinct modes of macrophage recognition for apoptotic and necrotic cells are not specified exclusively by phosphatidylserine exposure. Mol Biol Cell (2001) 12:919-30. doi:10.1091/mbc.12.4.919

62. Teinman RM, Brodie SE, Cohn ZA. Membrane flow during pinocytosis. A stereologic analysis. J Cell Biol (1976) 68:665-87. doi:10.1083/jcb.68.3.665

63. Norbury CC, Hewlett LJ, Prescott AR, Shastri N, Watts C. Class I MHC presentation of exogenous soluble antigen via macropinocytosis in bone marrow macrophages. Immunity (1995) 3:783-91. doi:10.1016/10747613(95)90067-5

64. Sallusto F, Cella M, Danieli C, Lanzavecchia A. Dendritic cells use macropinocytosis and the mannose receptor to concentrate macromolecules in the major histocompatibility complex class II compartment: downregulation by cytokines and bacterial products. J Exp Med (1995) 182:389-400. doi:10.1084/jem.182.2.389

65. Rock KL, Shen L. Cross-presentation: underlying mechanisms and role in immune surveillance. Immunol Rev (2005) 207:166-83. doi:10.1111/j. 0105-2896.2005.00301.x

66. Krysko DV, Denecker G, Festjens N, Gabriels S, Parthoens E, D’Herde K, et al. Macrophages use different internalisation mechanisms to clear apoptotic and necrotic cells. Cell Death Differ (2006) 13:2011-22. doi:10.1038/ sj.cdd. 4401900

67. Hochreiter-Hufford A, Ravichandran KS. Clearing the dead: apoptotic cell sensing, recognition, engulfment, and digestion. Cold Spring Harb Perspect Biol (2013) 5(1):a008748. doi:10.1101/cshperspect.a008748

68. Ellerman JE, Brown CK, de Vera M, Zeh HJ, Billiar T, Rubartelli A, et al. Masquerader: high mobility group box-1 and cancer. Clin Cancer Res (2007) 13(10):2836-48. doi:10.1158/1078-0432.CCR-06-1953

69. Rosenberger CM, Scott MG, Gold MR, Hancock RE, Finlay BB. Salmonella typhimurium infection and lipopolysaccharide stimulation induce similar changes in macrophage gene expression. J Immunol (2000) 164:5894-904. doi:10.4049/jimmunol.164.11.5894

70. Wardrop SL, Wells C, Ravasi T, Hume DA, Richardson DR. Induction of Nramp2 in activated mouse macrophages is dissociated from regulation of the Nramp1, classical inflammatory genes, and genes involved in iron metabolism. J Leukoc Biol (2002) 71:99-106. doi:10.1189/jlb.71.1.99

71. Bono H, Kasukawa T, Hayashizaki Y, Okazaki Y. READ: RIKEN expression array database. Nucleic Acids Res (2002) 30:211-3. doi:10.1093/ nar/30.1.211

72. Miki R, Kadota K, Bono H, Mizuno Y, Tomaru Y, Carninci P, et al. Delineating developmental and metabolic pathways in vivo by expression profiling using the RIKEN set of 18,816 full-length enriched mouse cDNA arrays. Proc Natl Acad Sci U S A (2001) 98:2199-204. doi:10.1073/ pnas. 041605498
73. Barron KD. The microglial cell. A historical review. JNeurol Sci (1995) 134:57-68. doi:10.1016/0022-510X(95)00209-K

74. Kreutzberg GW. Microglia: a sensor for pathological events in the CNS. Trends Neurosci (1996) 19:312-8. doi:10.1016/0166-2236(96)10049-7

75. Williams K, Alvarez X, Lackner AA. Central nervous system perivascular cells are immunoregulatory cells that connect the CNS with the peripheral immune system. Glia (2001) 36:156-64. doi:10.1002/glia.1105

76. Thomas WE. Brain macrophages: on the role of pericytes and perivascular cells. Brain Res Brain Res Rev (1999) 31:42-57. doi:10.1016/S0165-0173 (99)00024-7

77. Hume DA, Ross IL, Himes SR, Sasmono RT, Wells CA, Ravasi T. The mononuclear system revisited. JLeuk Biol (2002) 72:621-7. doi:10.1189/ jlb.72.4.621

78. Pham TH, Benner C, Lichtinger M, Schwarzfischer L, Hu Y, Andreesen R, et al. Dynamic epigenetic enhancer signatures reveal key transcription factors associated with monocytic differentiation states. Blood (2012) 119(24): e161-71. doi:10.1182/blood-2012-01-402453

79. Schmidt SV, Krebs W, Ulas T, Xue J, Baßler K, Günther P, et al. The transcriptional regulator network of human inflammatory macrophages is defined by open chromatin. Cell Res (2016) 26(1):151-70. doi:10.1038/cr.2016.1

80. Netea MG, Joosten LA, Latz E, Mills KH, Natoli G, Stunnenberg HG, et al. Trained immunity: a program of innate immune memory in health and disease. Science (2016) 352(6284):aaf1098. doi:10.1126/ science.aaf 1098

81. Raggi F, Pelassa S, Pierobon D, Penco F, Gattorno M, Novelli F, et al. Regulation of human macrophage M1-M2 polarization balance by hypoxia and the triggering receptor expressed on myeloid cells-1. Front Immunol (2017) 8:1097. doi:10.3389/fimmu.2017.01097

82. Movahedi K, Laoui D, Gysemans C, Baeten M, Stangé G, Van den Bossche J, et al. Different tumor microenvironments contain functionally distinct subsets of macrophages derived from Ly6C (high) monocytes. Cancer Res (2010) 70(14):5728-39. doi:10.1158/0008-5472.CAN-09-4672

83. Leblond MM, Gérault AN, Corroyer-Dulmont A, MacKenzie ET, Petit E, Bernaudin $M$, et al. Hypoxia induces macrophage polarisation and re-education toward an M2 phenotype in U87 and U251 glioblastoma models. Oncoimmunology (2016) 5(1):e1056442. doi:10.1080/21624 02X.2015.1056442

84. Chaturvedi P, Gilkes DM, Takano N, Semenza GL. Hypoxia-inducible factor-dependent signaling between triple-negative breast cancer cells and mesenchymal stem cells promotes macrophage recruitment. Proc Natl Acad Sci U S A (2014) 111:E2120-9. doi:10.1073/pnas.1406655111

85. Semenza GL. Regulation of mammalian O2 homeostasis by hypoxiainducible factor 1. Annu Rev Cell Dev Biol (1999) 15:551-78. doi:10.1146/ annurev.cellbio.15.1.551

86. Rius J, Guma M, Schachtrup C, Akassoglou K, Zinkernagel AS, Nizet V, et al. NF-kappaB links innate immunity to the hypoxic response through transcriptional regulation of HIF-1a pha. Nature (2008) 453(7196):807-11. doi:10.1038/nature06905

87. Nizet V, Johnson RS. Interdependence of hypoxic and innate immune responses. Nat Rev Immunol (2009) 9(9):609-17. doi:10.1038/nri2607

88. Imtiyaz HZ, Simon MC. Hypoxia-inducible factors as essential regulators of inflammation. Curr Top Microbiol Immunol (2010) 345:105-20. doi:10.1007/82_2010_74

89. Greenman C, Stephens P, Smith R, Dalgliesh GL, Hunter C, Bignell G, et al. Patterns of somatic mutation in human cancer genomes. Nature (2007) 446:153-8. doi:10.1038/nature05610

90. Rothlin CV, Ghosh S, Zuniga EI, Oldstone MB, Lemke G. TAM receptors are pleiotropic inhibitors of the innate immune response. Cell (2007) 131:1124-36. doi:10.1016/j.cell.2007.10.034

91. Zou W, Wolchok JD, Chen L. PD-L1 (B7-H1) and PD-1 pathway blockade for cancer therapy: mechanisms, response biomarkers, and combinations. Sci Transl Med (2016) 8:328rv4. doi:10.1126/scitranslmed.aad7118

92. Topalian SL, Hodi FS, Brahmer JR, Gettinger SN, Smith DC, McDermott DF, et al. Safety, activity, and immune correlates of anti-PD-1 antibody in cancer. N Engl J Med (2012) 366(26):2443-54. doi:10.1056/NEJMoa1200690

93. Chao MP, Alizadeh AA, Tang C, Myklebust JH, Varghese B, Gill S, et al. Anti-CD47 antibody synergizes with rituximab to promote phagocytosis and eradicate non-Hodgkin lymphoma. Cell (2010) 142:699-713. doi:10.1016/j. cell.2010.07.044 
94. Gordon SR, Maute RL, Dulken BW, Hutter G, George BM, McCracken MN, et al. PD-1 expression by tumour-associated macrophages inhibits phagocytosis and tumour immunity. Nature (2017) 545:495-9. doi:10.1038/nature22396

95. Oldenborg PA, Zheleznyak A, Fang YF, Lagenaur CF, Gresham HD, Lindberg FP. Role of CD47 as a marker of self on red blood cells. Science (2000) 288:2051-4. doi:10.1126/science.288.5473.2051

96. Tsai RK, Discher DE. Inhibition of "self" engulfment through deactivation of myosin-II at the phagocytic synapse between human cells. J Cell Biol (2008) 180:989-1003. doi:10.1083/jcb.200708043

97. Ogden CA, deCathelineau A, Hoffmann PR, Bratton D, Ghebrehiwet B, Fadok VA, et al. C1q and mannose binding lectin engagement of cell surface calreticulin and CD91 initiates macropinocytosis and uptake of apoptotic cells. J Exp Med (2001) 194:781-95. doi:10.1084/jem.194.6.781

98. Hoffmann PR, deCathelineau AM, Ogden CA, Leverrier Y, Bratton DL, Daleke DL, et al. Phosphatidylserine (PS) induces PS receptor-mediated macropinocytosis and promotes clearance of apoptotic cells. J Cell Biol (2001) 155:649-59. doi:10.1083/jcb.200108080

99. Chao MP, Jaiswal S, Weissman-Tsukamoto R, Alizadeh AA, Gentles AJ, Volkmer J, et al. Calreticulin is the dominant pro-phagocytic signal on multiple human cancers and is counterbalanced by CD47. Sci Transl Med (2010) 2:63ra94. doi:10.1126/scitranslmed.3001375

100. Gardai SJ, McPhillips KA, Frasch SC, Janssen WJ, Starefeldt A, MurphyUllrich JE, et al. Cell-surface calreticulin initiates clearance of viable or apoptotic cells through trans-activation of LRP on the phagocyte. Cell (2005) 123:321-34. doi:10.1016/j.cell.2005.08.032
101. Feng M, Chen JY, Weissman-Tsukamoto R, Volkmer JP, Ho PY, McKenna KM, et al. Macrophages eat cancer cells using their own calreticulin as a guide: roles of TLR and Btk. Proc Natl Acad Sci U S A (2015) 112(7):2145-50. doi:10.1073/pnas.1424907112

102. Ansell SM, Lesokhin AM, Borrello I, Halwani A, Scott EC, Gutierrez M, et al. PD-1 blockade with nivolumab in relapsed or refractory Hodgkin's lymphoma. N Engl J Med (2015) 372:311-9. doi:10.1056/ NEJMoa 1411087

103. Sakakura K, Takahashi H, Kaira K, Toyoda M, Murata T, Ohnishi H, et al. Relationship between tumor-associated macrophage subsets and CD47 expression in squamous cell carcinoma of the head and neck in the tumor microenvironment. Lab Invest (2016) 96(9):994-1003. doi:10.1038/ labinvest. 2016.70

Conflict of Interest Statement: The authors declare that the research was conducted in the absence of any commercial or financial relationships that could be construed as a potential conflict of interest.

Copyright (c) 2018 Mehrabi, Amini and Mehrabi. This is an open-access article distributed under the terms of the Creative Commons Attribution License (CC BY). The use, distribution or reproduction in other forums is permitted, provided the original author(s) and the copyright owner are credited and that the original publication in this journal is cited, in accordance with accepted academic practice. No use, distribution or reproduction is permitted which does not comply with these terms. 